\title{
Subjetividad y culpabilidad
}

\author{
GUILLERMO HURTADO \\ Instituto de Investigaciones Filosóficas \\ Universidad Nacional Autónoma de México \\ gmhp@servidor.unam.mx
}

\begin{abstract}
Resumen: Ésta es una nota crítica del libro Culpabilidad y resistencia de Óscar Martiarena. Se afirma que el autor no ofrece suficientes datos para probar la tesis central del libro que consiste en que los indios del virreinato se resistieron a convertirse en conciencias individuales culpables, tal como pretendían los sacerdotes católicos que les inculcaban la práctica de la confesión. También se sostiene que no es correcta la manera en la que Martiarena conecta las nociones de autonomía y culpabilidad.
\end{abstract}

Palabras clave: subjetividad, confesión, historia del México Colonial

1. Óscar Martiarena ha hecho uso de herramientas filosóficas, en particular foucaultianas, para estudiar algunos momentos de la historia de México. En un agudo ensayo sobre el método de Sahagún ("El indio como objeto de conocimiento", Diánoia, vol. XLIV, 1998), Martiarena se había ocupado de la cuestión de la conformación del indio como objeto de conocimiento. En Culpabilidad y resistencia: ensayo sobre la confesión en los indios de la Nueva España (Universidad Iberoamericana, México, 1999), examina la manera en que la imposición de la confesión auricular pretendía moldear la subjetividad del indio. A partir de un análisis cuidadoso y esclarecedor de diversos manuales y documentos sobre la confesión de indios en la Nueva España, Martiarena llega a conclusiones que nos obligan a revisar no sólo nuestra visión de la evangelización durante el virreinato, sino algo más amplio y hondo, a saber, la historia misma de la subjetividad en México.

Para Martiarena — siguiendo de cerca a Jean Delumeau—, la práctica de la confesión dentro de la Iglesia católica tiene como propósito crear primero, y apuntalar después, lo que podemos llamar una conciencia individual culpable, i.e., una conciencia de sí bajo el signo de la culpabilidad. De esta manera, la práctica de la confesión obliga al sujeto a examinar su vida, a construirla, incluso, desde la perspectiva del pecado. La conclusión del estudio de Martiarena, su tesis principal, es que, desde el siglo XVI hasta el XVIII, los indios se resistieron de una manera muy hábil a la culpabilización que les era demandada por sus confesores españoles, i.e., que a lo largo del periodo colonial lucharon para no convertirse en conciencias individuales culpables (p. 220). El argumento que ofrece Martiarena para llegar a esta conclusión es el siguiente. Los primeros cronistas franciscanos contaron que los indios recién convertidos no sólo habían adoptado 
de manera exitosa la práctica de la confesión, sino que mostraban deseos de confesarse y arrepentimiento genuino al hacerlo. Además, los cronistas franciscanos contaban que antes de la conquista los indios ya tenían practicas religiosas parecidas a la confesión cristiana. Sin embargo, cronistas de otras órdenes señalaron que encontraban dificultades en la confesión de indios. Los indios no mostraban culpa alguna, no hacían un recuento completo de sus pecados, no respondían satisfactoriamente a las preguntas del confesor, ante la presión eran evasivos o se quedaban callados; además, eran sospechosos de ocultar sus prácticas idolátricas. Los confesionarios de los siglos XVII y XVIII indican que las dificultades que encontraban los confesores eran mayores. Los autores de los confesionarios intrepretaron el comportamiento inadecuado de los indios como resultado del hecho de que los indios eran rústicos, de poco talento, de poca capacidad, que no sabían contar, que no tenían memoria, ni culpa alguna. A principios del XVIII, un confesor agustino - Manuel Pérez- añadió a estos calificativos uno más: son hábiles para escapar a la culpabilización necesaria. Martiarena interpreta estas dificultades descritas por los confesores como una resistencia de los indios a la culpabilización exigida en el confesionario. Lo que los confesores veían como rusticidad, mala memoria, incapacidad para sentir culpa, etc., era, en realidad, una resistencia - consciente o inconsciente- de los indios a convertirse en conciencias individuales culpables y a abandonar sus creencias ancestrales. La opinión de Manuel Pérez, según Martiarena, era la correcta. Los indios mostraron, a lo largo de tres siglos, ser hábiles para eludir la culpabilización que se les exigía en el confesionario.

En lo que sigue haré algunos comentarios críticos al libro de Martiarena. Mis críticas serán de dos tipos. Unas son metodológicas; voy a sostener que la base probatoria de la hipótesis de Martiarena es endeble. Las otras son conceptuales; me parece que Martiarena se equivoca al conectar las nociones de culpabilidad y de autonomía de la manera como lo hace en su libro.

2. Comencemos con las críticas metodológicas. Hay dos versiones de la tesis del libro que hemos de distinguir:

(H1) Los indios no tenían originalmente una conciencia individual culpable y, por ello, se resistieron, durante todo el virreinato, a tener una - en este caso, la que les querían imponer los sacerdotes católicos españoles.

(H2) Los indios tenían una conciencia individual culpable que era propia de su cultura, pero durante el virreinato se resistieron a adoptar la que les querían imponer los sacerdotes españoles. (Por lo que nos cuenta Sahagún, parece que los indios tenían, desde an- 
tes de la conquista, los conceptos de acción individual pecaminosa y de expiación individual.)

No queda claro si Martiarena sostiene (H1) o (H2). Si adoptamos (H2), diremos que los indios se resistieron a la sustitución de un esquema de culpabilización por otro, lo que supone que se aferraban a su esquema original. Pero si adoptamos (H1), entonces diremos que los indios se resistían a constituirse como conciencias individuales culpables, i.e., que querían defender una manera de verse a sí mismos que no estuviera determinada por la culpabilidad individual.

Cualquiera que sea la versión elegida, la hipótesis de Martiarena es importante y merece ser examinada con cuidado. Sin embargo, me parece que la base probatoria que ofrece no es suficiente para elegir entre (H1) y (H2) y, por lo mismo, no permite aceptar alguna de ellas con un mayor grado de probablidad. Esto no significa que piense que la hipótesis sea falsa. Por el contrario, tiendo a creer que alguna versión de ella es verdadera; sin embargo, es preciso hacer más para apuntalarla y precisarla.

Martiarena tampoco ofrece suficientes elementos para descartar las siguientes dos hipótesis alternativas que podrían plantearse con base en el mismo conjunto de datos que examina en su libro:

(A1) Las dificultades de las que hablaban los confesores no eran mecanismos de resistencia frente a la culpabilización, sino dificultades genuinas de algunos indios para efectuar la práctica de la confesión. Es posible que las habilidades requeridas para la confesión -mnemotécnicas, narrativas, expresivas, etc.- de los indios del siglo XVIII hayan sido inferiores a las de los indios del XVI, o que dichas habilidades estuviesen menos desarrolladas entre los indios de las zonas apartadas, que se evangelizaron en el XVII y el XVIII, que entre los indios de las zonas de mayor desarrollo evangelizadas antes. Esto explicaría las diferencias que hay entre el testimonio de los franciscanos en el siglo XVI y el de los demás confesores en el XVIII.

(A2) Había, en efecto, resistencia de los indios en el confesionario, pero no a la culpabilización, sino a confesar de manera explícita y detallada las culpas a los sacerdotes por desconfianza y por temor a represalias. Es más, podríamos imaginar que en el siglo XVI los indios no se resistían a la confesión con los franciscanos porque confiaban en ellos, pero que en el XVIII ya no confiaban en los sacerdotes, que, a su vez, habían dejado de tener la actitud tolerante y comprensiva de los primeros misioneros. Esta hipótesis podría apoyarse en la afirmación del dominico fray Antonio de Remesal, en 1619, de que los indios no se confesaban porque 
sospechaban que el sacerdote fuera a violar el secreto del confesionario para perjudicarlos (p. 96).

La primera hipótesis alternativa, (A1), tiene la ventaja de ser más sencilla y apegada a lo que pensaban los confesores españoles, que tenían un contacto directo y diario con los indios. La segunda hipótesis, (A2), tiene la ventaja de que si bien acepta que hubo una resistencia a la confesión, la explicaría en términos sociales más fáciles de comprobar que los términos subjetivos de la hipótesis de Martiarena.

Algunas de las dificultades para elegir entre (H1) y (H2) y para descartar (A1) y (A2) parten del hecho de que Martiarena sólo ha contado la mitad de la historia y que, por lo tanto, sus conclusiones dependen tan sólo de esa mitad. Lo que nos ha contado Martiarena es lo que pensaban los sacerdotes acerca de la práctica de la confesión de los indígenas, pero no sabemos qué es lo que pensaban los indios acerca de dicha práctica. Su conclusión está inferida a partir de lo que decían los españoles, no los propios indios. Para saber lo que pensaban los indios habría que examinar documentos escritos en lenguas indígenas donde se hiciera alguna mención de la confesión, o de la culpa o del pecado. De no existir tales documentos, podría hacerse un estudio de los confesionarios escritos en lenguas indígenas. Sería interesante, por ejemplo, analizar los conceptos que utilizaban los indígenas para confesarse en sus idiomas. Este trabajo de investigación queda pendiente para apuntalar mejor la hipótesis de Martiarena. Pero no se tome esto como un reproche. La contribución de su libro consiste en haber formulado la hipótesis en cuestión sobre una base plausible. Mi crítica se limita a que dicha base es aún insuficiente para dar a la hipótesis precisión y firmeza.

3. Un sujeto con una conciencia culpable, dice Martiarena, no puede valorarse a sí mismo, ni su individualidad (p. 62). Pero Martiarena va más allá. Un sujeto con una conciencia individual culpable, nos dice, no puede ser autónomo en el sentido kantiano, i.e., darse a sí mismo una ley. La exigencia de los sacerdotes españoles de que los indios aceptaran la práctica de la confesión y la llevaran a cabo de manera correcta, para que se aceptaran plenamente como conciencias culpables, era, según Martiarena, un atentado contra su autonomía. Citemos las palabras finales del libro que nos ocupa:

Mediante un procedimiento similar al que usan quienes para reconocer al otro le exigen una identidad previamente determinada, frente a las resistencias de los indios, los confesores optaron por identificarlos a través de un estigma que los reducía de antemano. Estigma que después de varios siglos aún los señala. Mientras Europa ilustraba y se afanaba por garantizar la formación de individuos autónomos, en la Nueva España los confesores perseguían a los indios 
por sus costumbres y su indolencia, por renunciar a constituirse como conciencias individuales culpables. También por su silencio. Hoy, [...] rompiendo su impenetrable silencio y el estigma que todavía los condena, algunos indios en México hacen oír su voz, la misma que enmudeciera frente a las demandas de los confesores, exigiendo lo que una práctica como la confesión sacramental no les dio ni podía darles: autonomía. Es decir, darse a sí mismos una ley que están dispuestos a seguir. (p. 221)

Parece que la noción de autonomía que tiene en mente Martiarena es la kantiana. Pero dudo que los indios del virreinato que se resistían a adoptar la culpabilización cristiana fuesen autónomos en el sentido kantiano y lo mismo diría respecto a los indios que, hoy en día, como dice Martiarena, alzan la voz. No está de más distinguir entre la autonomía kantiana - que desemboca en una legislación moral universal, i.e., que vale para todas las personas en cuanto seres racionales y libres- y la autonomía política o cultural o religiosa de una comunidad que no pretende llegar a normas morales o legales basadas en principios de racionalidad práctica que valgan para todas las personas, sino más bien en normas y creencias relativas a dicha comunidad, lo que entre algunos indios se llama "el costumbre". Es un hecho que los sacerdotes españoles negaban a los indios del virreinato - como a los mestizos y a los criollos, y a los mismos peninsulares- la capacidad de erigirse en individuos autónomos. Pero a mí me parece que si bien la religión y la moral de los indios del virreinato eran las que ellos mismos se habían dado, tenían un fundamento muy distinto del que pretendían encontrar, para su propia religión y moral, los ilustrados europeos a los que refiere Martiarena. Dicho en otras palabras, si bien es verdad que los sacerdotes españoles aplastaban la autonomía de los indios, también lo es que los sacerdotes indígenas hacían lo mismo. Los graves conflictos religiosos en la misma zona del país en la que algunos indígenas han exigido mayor autonomía política muestran que en la mayoría de dichas comunidades hay, todavía hoy en día, muy poco espacio para la autonomía, la tolerancia y la pluralidad.

Pero el asunto de fondo es la conexión tan estrecha que Martiarena establece entre la conciencia individual culpable y la falta de autonomía. A mí me parece, por el contrario, que uno podría ser un individuo autónomo y tener, al mismo tiempo, una conciencia individual culpable. ¿Acaso no podría sentirme culpable por no tener la fuerza de voluntad de seguir al pie de la letra la ley moral que yo mismo me he dado? ¿Y acaso esta culpa no podría teñir por completo la manera en que yo considero mi propia persona? Me parece que Martiarena tendría que responder estas preguntas antes de ligar de la manera como lo hace las nociones de autonomía y culpabilidad. 
4. A pesar de las críticas metodológicas y conceptuales que he hecho a las tesis centrales de Culpabilidad y resistencia, quiero reiterar que me parece que es un libro importante, pionero en muchos aspectos, que abre y traza un sendero de investigación prometedor en nuestra historia de las mentalidades. El libro de Martiarena se inscribe en una tradición de hacer historia filosófica a la que pertenecen algunos de nuestros mejores historiadores y filósofos.

Recibido el 14 de enero de 2002, aceptado el 19 de marzo de 2002 